\title{
Achieving sustainable development goals on no poverty and zero hunger: Does technical efficiency of Ghana's maize farmers matter?
}

\author{
Camillus Abawiera Wongnaa* and Dadson Awunyo-Vitor
}

\begin{abstract}
Background: Whether or not maize farmers are technically efficient determines their choice of productivity improvement strategy and very important for achieving the sustainable development goals on no poverty and zero hunger. This study examined technical efficiency and its determinants of Ghana's maize farmers. Analysis of the determinants is crucial to devising strategies aimed at improving technical efficiencies of the farmers as well as ensuring no poverty and zero hunger.
\end{abstract}

Methods: The study used cross-sectional data collected from 576 maize farmers in the four main agro-ecological zones of Ghana with the aid of structured questionnaire. Descriptive statistics and the stochastic frontier production function were the methods of analysis used.

Results: The results showed that the mean technical efficiency estimate for maize farmers in Ghana was 58.1\%. They also revealed that an increase in educational level, maize farming experience, extension contact as well as uses of fertilizer and improved seeds would increase the technical efficiency of maize producers in Ghana. Similarly, male Ghanaian maize farmers were more technically efficient than female farmers. Furthermore, membership of a farmer association will increase their technical efficiencies. Finally, an increase in farm size and land fragmentation will decrease technical efficiency of the maize farmers.

Conclusion: Efficiency improvement programmes by stakeholders in the maize industry could target literate maize farmers since education enhances the managerial and technical skills of farmers and also increase farmers' ability to utilize existing technologies. Ministry of Food and Agriculture (MOFA) could also liaise with Ministry of Education to provide maize farmers with no formal education with special training prior to introducing new efficiency enhancing programmes to them. MOFA should analyse the problems extension officers face in the discharge of their duties to pave the way for the provision of appropriate incentives to extension officers by stakeholders in the maize industry.

Keywords: Determinants, Maize, Technical efficiency, Stochastic frontier analysis

\section{Background}

The importance of the contribution of maize production to economic growth, poverty alleviation, food security, gross domestic product, employment and incomes in Ghana cannot be overemphasized. For most rural households in Ghana, maize is the main staple food and an ideal crop whose increased productivity has the potential

\footnotetext{
*Correspondence: wongnaaa@yahoo.com
}

Department of Agricultural Economics, Agribusiness and Extension,

Kwame Nkrumah University of Science and Technology, Private Mail Bag,

University Post Office, Kumasi, Ghana to support Ghana's strive to meeting the sustainable development goals on no poverty and zero hunger. However, there has been an unstable trend in the country's maize production over the last two decades, which threatens household food security and income sources [27]. Because maize production is critical for the overall process of social and economic development of Ghana, it is crucial that the country takes steps, especially through research, to help grow and develop the maize sector. A very important factor that will help sustain an increase in maize production is an increase in its productivity driven 
by increase in economic efficiency of its producers [6]. Economic efficiency is incomplete if technical efficiency is not studied [19]. The farmer's ability to achieve maximum output with available resources is referred to as technical efficiency. Whether or not maize farmers are technically efficient determines their choice of productivity improvement strategy and very important for achieving the sustainable development goals on no poverty and zero hunger. This is because, if they are technically efficient, then new inputs or production technologies will be required to shift the production curve or frontier upward. Conversely, if their productivities are below potential yields, then their technical efficiencies could be improved by dealing with the causes of technical inefficiency [32].

Various studies have analysed technical efficiency of Ghana's maize farmers even though the scopes of these studies did not cover the entire nation like the current study and in most of these studies, the stochastic frontier analysis procedure was employed as the method of analysis. In spite of the drivers of technical efficiency identified in previous studies, maize farmers continue to experience low yields [27] depicting the failure of recommendations of previous studies to help address the productivity and efficiency challenges farmers have faced over the years. By way of literature review, [2] employed the stochastic frontier analysis procedure and estimated the technical efficiency of maize farmers in Northern Ghana to be $74 \%$. The study concluded that their technical efficiencies were positively influenced by agricultural mechanization, experience and gender. Sienso et al. [38], studying the technical efficiency of maize production in Nkoranza district of BrongAhafo Region of Ghana using the stochastic frontier analysis procedure, found the technical efficiency of the farmers to be $91 \%$. In this study, variety of maize cultivated, male gender, farming experience and number of extension visits were found to influence technical efficiency of the farmers. Also, using the stochastic frontier analysis procedure, [24] reported a technical efficiency of $51 \%$ for maize farmers in Ghana's eastern region. The findings from the inefficiency model of this study also showed that technical efficiencies of the farmers were determined by contact with agricultural extension workers, membership of a farmer association, number of meetings held by association, formal education and use of credit. Bempomaa and Acquah [13] also employed the stochastic frontier analysis procedure and reported a mean technical efficiency of $67 \%$ for maize farmers in the Ejura/Sekyedumase district of Ashanti region of Ghana. According to the study, the technical efficiencies of the farmers were influenced by their ages, male gender as well as off-farm activities. In addition, [3] estimated the technical efficiency of maize farmers across three agro-ecological zones of Ghana using the stochastic frontier analysis procedure to be $64.1 \%$. The results of this study also revealed that their technical efficiencies were positively influenced by male gender, contact with agricultural extension officers, farmer's age, access to credit, whether or not farmer owned land and mono-cropping. Furthermore, in analysing the technical efficiency and production risk in Ghana's maize production, [31] estimated the technical efficiency of the farmers to be $62 \%$ with the combined farm specific factors explaining technical efficiency variations. Finally, [20] obtained a mean technical efficiency of $58 \%$ for maize farmers in the Mfantseman Municipality of Ghana by the stochastic frontier analysis approach. According to the study, the mean technical efficiency was influenced by size of household, male gender, years of schooling, off-farm income as well as farmer's age.

In addition to the variables considered in the aforementioned studies, other variables including land fragmentation, access to ready market, use of fertilizer, pesticides and improved seeds as well as farming in particular agro-ecological zones may also influence technical efficiency. This study analyses Ghana's maize farm level technical efficiency variations caused by the aforementioned factors. The study provides a nationwide analysis of technical efficiency of Ghana's maize farmers by using data from the Northern Savannah, Transitional, Forest and Coastal Savannah zones. This is important because existing similar studies [2, 13, 20, $24,31,38$ ] used data that were restricted to only certain districts, municipalities or agro-ecological zones which are not very representative of the nation. Also, it has been argued that technical efficiency of maize farmers might differ depending on their respective agro-ecological zones as they might be using different technologies. The current study provides evidence of same or similar technologies used by maize farmers across Ghana's agro-ecological zones and therefore employs the stochastic production frontier instead of the metafrontier.

\section{Methods}

\section{Study area and data collection}

The study was conducted in Ghana's four main agro-ecological zones, namely Northern Savannah, Transitional, Forest and Coastal Savannah zones. The Northern Savannah zone comprises the three northern regions, namely Northern, Upper West and Upper East regions. The Transitional zone is made up of the Brong-Ahafo region and the northern part of Ashanti region. The Forest zone consists of the middle and central parts of Ashanti region as well as the Eastern and Western regions. Finally, the 
Coastal Savannah zone comprises the coastal parts of Greater Accra, Central and Volta regions of Ghana.

The study used primary cross-sectional data which was collected from 576 maize farmers with the aid of a structured questionnaire. Generally, the questionnaire comprised four sections. The first section consisted of identification of the enumerator, the respondent as well as the district and operational area of the respondent. The second section included questions on maize producers' personal and household characteristics. The third section dealt with questions on inputs or resources employed in maize production, while the fourth section posed questions on the output of maize and its marketing. Basically, the study employed multi-stage sampling technique. In stage one (1) of the sampling design, two districts/municipalities were purposively selected from each zone based on the level of maize production [27]. The selected districts/municipalities were East Gonja and West Mamprusi (Northern Savannah zone), Nkoranza and Ejura Sekyedumase (Transitional zone), Fanteakwa and Sekyere South (Forest zone) and Gomoa and Ketu (Coastal Savannah zone). In the second stage, nine (9) villages or communities were randomly selected from each district/municipality. Stage three involved random sampling of eight (8) maize farmers from lists of maize farmers obtained from agricultural extension agents operating in the various villages/communities.

\section{Analytical framework}

The study employed descriptive statistics in analysis of socio-economic characteristics of maize farmers in Ghana. The stochastic frontier analysis approach was also employed in analysing the technical efficiency of the farmers. The function was independently proposed and defined by $[5,26]$ as;

$$
y_{i}=f\left(x_{i} ; \beta\right) \exp ^{v_{i}-u_{i}} \text { where } i=1,2, \ldots, N
$$

where $y_{i}$ is output of the $i$ th farmer; $f\left(x_{i} ; \beta\right)$ is a suitable production function, $x_{i}$ is a vector of farm inputs, $\beta$ is a vector of parameters to be estimated, and $N$ is the sample size. $v_{i}$, which represents a random error, has zero mean and is assumed to be symmetric and independently distributed as $N\left(0 ; \sigma^{2} v,\right)$ and is particularly related to random factors which cannot be controlled by the farmer such as measurement errors and weather factors. $u_{i}$, which is non-negative truncated half normal, random variable, $N\left(0 ; \sigma^{2} v\right)$, is linked to the technical inefficiency of the farmer.

According to [37], technical efficiency of a farm firm is calculated using the ratio of observed output to the potential or frontier output. That is,

$$
\begin{aligned}
\text { Technical efficiency } & =\mathrm{TE}_{i}=\frac{y_{i}}{y_{i}^{*}} \\
& =\frac{f\left(x_{i} ; \beta\right) \exp ^{v_{i}-u_{i}}}{f\left(x_{i} ; \beta\right) \exp ^{v_{i}}}=\exp ^{-u_{i}}
\end{aligned}
$$

where $y_{i}$ is the highest or maximum predicted output for the $i$ th farm and $y_{i}^{*}$ is the potential or frontier output. In employing the stochastic frontier analysis approach, [16] present two estimation procedures. In the first procedure, in the absence of a specified clear distribution of the efficiency component, stochastic corrected ordinary least squares (COLS) is appropriate. On the other hand, maximum likelihood estimation (MLE) technique is employed as the estimation procedure if a clear distribution is specified. MLE is more efficient than COLS because it uses the specific distribution of the error term [22]. The stochastic frontier and the inefficiency model are jointly estimated using frontier computing packages such as FRONTIER, STATA and Limdep which apply MLE $[11,21]$. This study used STATA.

The selection of functional form is essential in employing the stochastic frontier analysis approach. The Cobb-Douglas production function introduces severe restriction on the technology employed in the farm by limiting the elasticities of production to be fixed and the input substitution elasticities to unity [43]. This is, however, not the case with the translog functional form. Diagnostically, to determine which functional form is more appropriate for the data collected, the generalized likelihood ratio test was employed as follows:

$$
\lambda=-2\left[\ln \frac{L\left(H_{0}\right)}{L\left(H_{1}\right)}\right]=-2\left[\ln L\left(H_{0}\right)-\ln L\left(H_{1}\right)\right]
$$

where $L\left(H_{0}\right)=$ value of the log-likelihood of the adopted model, $L\left(H_{1}\right)=$ value of the log-likelihood of the restricted model.

$\lambda$ has a Chi-square distribution with degree of freedom equal to number of restrictions. The main hypothesis tested is whether or not the Cobb-Douglas functional form fits the data collected in the study, given the trans$\log$ functional form. Cobb-Douglas functional form was rejected in favour of the translog functional form. After settling on the ideal functional form, separate stochastic production frontier (SPF) models were defined for maize farmers in different agro-ecological zones of Ghana. After the estimation of the separate stochastic production frontier (SPF) models, it was necessary to verify if maize farmers in the various agro-ecological zones shared the same technology. This was also done using a likelihood ratio (LR) test, where $L\left(H_{0}\right)$ is the value of the log-likelihood function for a stochastic production frontier estimated by pooling the data for all agro-ecological zones 
and $L\left(H_{A}\right)$ is the sum of the values of the log-likelihood functions from the individual stochastic production frontiers. The degree of freedom for the Chi-square statistic is the difference between the number of parameters estimated under $H_{A}$ and $H_{0}$. If the null hypothesis that the stochastic frontier for the pooled data exists is rejected in favour of the individual frontiers, then the data should not be pooled and in such a case, the metafrontier is the appropriate framework to estimate and compare technical efficiency across agro-ecological zones [12]. Empirically, the stochastic frontier translog production function is specified as:

$$
\ln y_{i}=\beta_{0}+\sum_{k=1}^{m} \beta_{k} \ln x_{k i}+\frac{1}{2} \sum_{k=1}^{m} \sum_{j=1}^{m} \beta_{k j} \ln x_{k i} \ln x_{j i}+v_{i}-u_{i}
$$

where $y_{i}=$ total quantity of output $(\mathrm{kg}), x_{i}=$ vector of inputs which includes $S E D=$ quantity of seed $(\mathrm{kg})$, $L A N D S Z=$ farm size (ha), $L A B=$ quantity of labour (Man-days), $C A P=$ capital (depreciated charges on farm tools and implements), $F E T=$ quantity of fertilizer $(\mathrm{kg})$, $M A N=$ quantity of manure $(\mathrm{kg}), P E T=$ quantity of pesticides (litres), $H E B=$ quantity of herbicides (litres), $m=$ number of production inputs, $i j=$ positive integers $(i \neq j), \beta^{\prime} s=$ vector of parameters to be estimated, $v_{i}$ and $u_{i}$ have their usual meanings. Empirically, the inefficiency model is also specified as:

$$
u_{i}=\delta_{0}+\sum_{m=1}^{N} \delta_{m} z_{i}
$$

where $z_{i}=$ vector of farmer characteristics thought to influence technical efficiency which includes $R O A D=$ access to good roads, measured as a dummy (1 for access to good road and 0 otherwise), $S E X=$ gender of maize farmer, measured as a dummy ( 1 for male and 0 for female), $A G E=$ age of maize farmer, measured in years, $E D U=$ educational level of maize farmer, measured in years of schooling, HOSIZE = household size, measured as number of family members living with maize farmer. $E X P=$ maize farming experience, measured in number of years in maize farming, $M G R O U P=$ membership of a farmer association, measured as a dummy ( 1 for membership of an association and 0 otherwise), $C R E D I T=$ access to credit, measured as a dummy (1 for access to credit and 0 otherwise), INCOME = previous year's maize income, measured in Ghana Cedis, NPLOTS $=$ land fragmentation, measured as a dummy (1 for owning more than one plot and 0 otherwise), NOEX$T V I=$ extension contact, measured in number of meetings of maize farmer with agricultural extension agents,
REDYMKT $=$ access to ready maize market, measured as a dummy ( 1 for available maize market and 0 otherwise), FERTus = use of inorganic fertilizer, measured as a dummy ( 1 for use of inorganic fertilizer and 0 otherwise), $P E S T$ T $=$ use of pesticides, measured as a dummy ( 1 for use of pesticides and 0 otherwise), SEDtyp $=$ seed variety planted by maize farmer, measured as a dummy ( 1 for improved variety and 0 for traditional variety), $N O S A V=$ living in the Northern Savannah zone, measured as a dummy ( 1 for living in Northern Savannah zone and 0 for living in the Coastal Savannah zone), TRASIT $=$ living in the Transitional zone, measured as a dummy ( 1 for living in Transitional zone and 0 for living in the Coastal Savannah zone), FOREST=living in the Forest zone, measured as a dummy ( 1 for living in Forest zone and 0 for living in the Coastal Savannah zone), $\delta=$ vector of parameters to be estimated. The parameters in the stochastic frontier production function and those of the inefficiency model can be jointly estimated in STATA [21]. The joint model generates variance parameters, i.e., $\lambda=\sigma_{u} / \sigma_{v}$, variance of the model, $\sigma$, variance of the stochastic model, $\sigma_{v}^{2}$, and variance of the inefficiency model, $\sigma_{u}^{2}$. Breusch Pagan statistic and variance inflation factor (VIF) were employed in testing for heteroscedasticity and multicollinearity, respectively. Also, the partial input elasticities can be calculated by taking the partial derivative of $y_{i}$ with respect to $x_{k i}$ in Eq. (4) and substituting the sample input means. This, according to $[1,45]$, is specified as:

$$
e_{j}=\frac{\partial \ln y_{i}}{\partial x_{k i}}=\beta_{k}+\sum_{j=1}^{m-1} \beta_{k j} \ln x_{j}+2 \beta_{k k} \ln x_{k}
$$

\section{Results and discussion}

\section{Socio-economic characteristics of the respondents}

The results presented in Table 1 showed that most of the respondents $(77.4 \%)$ were males, an indication of the popularity of males in Ghana's maize production than females. It could also be inferred from this study that both men and women could take maize production as a business and a source of employment. With majority of the farmers with ages within 18-45 years' bracket $(56.9 \%)$, the mean age was 45.15 years (Table 2). The implication was that the farmers were old. According to studies conducted by [20], [13] as well as [3], old age of farmers could adversely affect their technical efficiencies. The results in Tables 1 and 2 also showed that generally, majority of the farmers who took part in the survey (64.1\%) received at least six (6) years of formal education and this could help them operate close to the production frontier $[20,24,31]$ 
Table 1 Socio-economic characteristics of respondents. Source: Survey, 2015

\begin{tabular}{|c|c|c|}
\hline Variable & Frequency & $\%$ \\
\hline \multicolumn{3}{|l|}{ Ready market last year } \\
\hline No & 70 & 12.2 \\
\hline Yes & 506 & 87.8 \\
\hline Total & 576 & 100 \\
\hline \multicolumn{3}{|l|}{ Gender } \\
\hline Male & 446 & 77.4 \\
\hline Female & 130 & 22.6 \\
\hline Total & 576 & 100 \\
\hline \multicolumn{3}{|l|}{ Age group of farmers (years) } \\
\hline $18-45$ & 328 & 56.9 \\
\hline $46-60$ & 180 & 31.2 \\
\hline Greater than 60 & 68 & 11.8 \\
\hline Total & 576 & 100 \\
\hline \multicolumn{3}{|l|}{ Educational level of maize farmer } \\
\hline No formal education & 207 & 35.9 \\
\hline Primary school & 84 & 14.6 \\
\hline JHS/JSS/Middle school & 200 & 34.7 \\
\hline SHS/SSS & 69 & 12 \\
\hline Tertiary & 16 & 2.8 \\
\hline Total & 576 & 100 \\
\hline \multicolumn{3}{|l|}{ Number of plots } \\
\hline One plot & 454 & 78.8 \\
\hline More than one plot & 122 & 21.2 \\
\hline Total & 576 & 100 \\
\hline \multicolumn{3}{|l|}{ Group membership } \\
\hline No & 436 & 75.7 \\
\hline Yes & 140 & 24.3 \\
\hline Total & 576 & 100 \\
\hline \multicolumn{3}{|l|}{ Access to extension } \\
\hline No & 331 & 57.5 \\
\hline Yes & 245 & 42.5 \\
\hline Total & 576 & 100 \\
\hline \multicolumn{3}{|l|}{ Access to credit } \\
\hline No & 475 & 82.5 \\
\hline Yes & 101 & 17.5 \\
\hline Total & 576 & 100 \\
\hline \multicolumn{3}{|l|}{ Access to good roads } \\
\hline Bad (tarred with potholes/rough and marshy) & 292 & 50.7 \\
\hline $\begin{array}{l}\text { Good (asphalt/tarred but not asphalt/rough and } \\
\text { smooth) }\end{array}$ & 284 & 49.3 \\
\hline \multicolumn{3}{|l|}{ Fertilizer use } \\
\hline No & 207 & 35.9 \\
\hline Yes & 369 & 64.1 \\
\hline Total & 576 & 100 \\
\hline \multicolumn{3}{|l|}{ Pesticides use } \\
\hline No & 560 & 97.2 \\
\hline Yes & 16 & 2.8 \\
\hline \multicolumn{3}{|l|}{ Seed variety planted } \\
\hline Traditional & 346 & 60.1 \\
\hline
\end{tabular}

Table 1 (continued)

\begin{tabular}{lll}
\hline Variable & Frequency & $\%$ \\
\hline Improved & 230 & 39.9 \\
Total & 576 & 100 \\
Land fragmentation & & \\
Owned more than one plot & 223 & 38.7 \\
Owned only one plot & 353 & 61.3 \\
Total & 576 & 100 \\
\hline
\end{tabular}

Table 2 Descriptive statistics of quantities of inputs and output of respondents. Source: Survey, 2015

\begin{tabular}{lllll}
\hline Variable & Min & Max & Mean & Std Dev \\
\hline Size of farm (ha) & 0.22 & 69.81 & 2.92 & 12.7 \\
Number of farm plots & 1.00 & 7.000 & 1.53 & 0.78 \\
Quantity of fertilizer (kg) & 0.01 & 1114 & 211 & 143 \\
Quantity of herbicide (L) & 0.01 & 88.14 & 11.4 & 13.1 \\
Quantity of pesticide (L) & 0.02 & 36.21 & 9.13 & 5.21 \\
Number of extension visits/year & 0.00 & 7.000 & 2.74 & 4.81 \\
Quantity of labour (man-days) & 2.18 & 8107 & 104.0 & 94.5 \\
Quantity of manure (kg) & 0.01 & 1019 & 99.3 & 154 \\
Capital (depreciation) & 40.0 & 2499.9 & 558 & 766 \\
Quantity of output (Mt) & 0.01 & 10.414 & 4.874 & 5.88 \\
\hline
\end{tabular}

With a high mean household size of 7.61 (Table 2), the labour available to the farmers could be enhanced, thereby making farmers carry out husbandry practices on time which could help improve their technical efficiencies [20]. Generally, the respondent maize farmers had 14 years of experience in maize farming. With high experience levels, it will not be surprising if farmers' technical efficiencies are high given that such farmers are supplied with the required productivity enhancing technologies [2, 38]. Also presented in Table 1 is that $57.5 \%$ of the farmers in the sample had no access to extension service, and for those who received extension service, extension officers visited them thrice (Table 2), indicating poor services received by the farmers. This could cause little or no use of productivity enhancing technologies since farmers will likely be unaware of these technologies because those who are supposed to disseminate the technologies to them (i.e., extension agents) are far from them. The results could be that the technical efficiency of the farmers would be relatively low [24, 38]. Also worthy of note is the fact that as high as $75.7 \%$ of the respondents were not members of any farmer group (Table 1). This could increase technical inefficiency of the farmers since most extension agents disseminate agricultural technologies through farmer groups [7, 14, 28]. In fact, most of the respondents $(82.5 \%)$ too received no credit 
from any source and this could stop or delay application of key production inputs to crops since farmers will have no money to purchase the inputs, thereby making them technically inefficient $[3,24]$.

The findings of the current study show that Ghana's maize production is basically on a small scale as the average farm size was estimated to be 2.86 ha (Table 2). Almost half of the sampled maize farmers (49.3\%) remarked they have access to good roads (asphalt/ tarred but not asphalt/rough and smooth) as against $50.7 \%$ of them that reported dilapidated nature of their roads (tarred with potholes/rough and marshy) (Table 1). Okoboi [30] emphasized the importance of good roads in the agricultural production and marketing process. According to the study, roads are needed for regular access to inputs and output markets. The average yield of maize grain produced in Ghana according to the results is $1800 \mathrm{~kg} / \mathrm{ha}$ (1.8 metric tonnes/ha) (Table 2). This is in line with MOFA's that the average yield of maize was 1.9 metric tonnes/ha instead of a potential of 6.0 metric tonnes/ha [27], indicating that maize yield is still low.

The study revealed that $60.1 \%$ of the respondents used traditional maize seeds, while $39.9 \%$ used improved seeds (Table 1 ). Most improved seeds are relatively high yielding so most farmers using traditional seeds could pose a negative effect on their technical efficiencies [38]. The average quantity of seed used per hectare for all the sampled maize farmers is $18 \mathrm{~kg}$ (Table 2). This is quite low, even though most farmers use traditional varieties and seeds are not difficult to come by since they can get it from their previous season. The results also show a $64.1 \%$ use of fertilizer (Table 1). Fertilizer supplies the crops with the required plant nutrients, and therefore, its use in recommended quantities is expected to improve the farmers' technical efficiencies [44]. The number of maize farmers using fertilizer is therefore quite high in the study only that the quantities applied by the farmers were lower than recommended rates. This corroborates the results obtained by [34] that use of fertilizer greatly exceeds earlier reports, even though the extent of use was $50 \%$ of the recommended rate. Use of pesticides is not very common among maize farmers in the study area as $97.2 \%$ of the farmers did not apply pesticides (Table 1 ). Farmers could therefore be technically inefficient if steps are not taken to improve pesticide usage. The situation could be worse today, especially with the recent invasion of the fall army worms which are reported to have destroyed vast maize farms which has threatened Ghana's ability to meet the sustainable development goals on no poverty and zero hunger.

\section{Stochastic frontier production function analysis of maize production}

Two likelihood ratio tests were conducted in the study. The first test was to ascertain the appropriateness of either Cobb-Douglas or translog functional form for the data, and the second was to confirm whether or not maize farmers in the four agro-ecological zones shared same or similar technologies. The results of the generalized likelihood ratio test rejected the stochastic frontier Cobb-Douglas production function in favour of the stochastic frontier translog production function as a fitting functional form for the data collected in all agro-ecological zones (Table 3). Table 5 presents the estimates of the stochastic production frontiers for the pooled and each agro-ecological zone from whose log-likelihoods the second likelihood ratio test was conducted. The results of the second likelihood ratio test examining whether or not the agro-ecological zones shared the same technology revealed that they shared the same technology as is not significant (Table 3). The implication is that there would be no reason for estimating a metafrontier production model. This suggests that the stochastic frontiers for maize farms in the four agro-ecological zones are not different and that any efficiency comparison across these four subsamples should be undertaken with respect to the pooled stochastic frontier instead of the metafrontier. The variance parameters for the chosen pooled

Table 3 Results of test of hypotheses

\begin{tabular}{|c|c|c|c|c|c|c|c|c|c|c|c|c|c|c|c|c|c|c|c|c|}
\hline \multirow[t]{2}{*}{ Restriction } & \multicolumn{4}{|l|}{ Pooled } & \multicolumn{4}{|c|}{ Northern Savannah } & \multicolumn{4}{|c|}{ Transitional } & \multicolumn{4}{|l|}{ Forest } & \multicolumn{4}{|c|}{ Coastal Savannah } \\
\hline & $L\left(H_{0}\right)$ & $\lambda$ & $x^{2}$ & $D$ & $L\left(H_{0}\right)$ & $\lambda$ & $x^{2}$ & $D$ & $L\left(H_{0}\right)$ & $\lambda$ & $x^{2}$ & $D$ & $L\left(H_{0}\right)$ & $\lambda$ & $x^{2}$ & $D$ & $L\left(H_{0}\right)$ & $\lambda$ & $x^{2}$ & $\bar{D}$ \\
\hline$H_{0}: \beta_{i j}=0$ & -98.2 & 38.2 & 23.3 & $R$ & -85.3 & 24.2 & 23.3 & $R$ & -99.4 & 52.5 & 23.3 & $R$ & -81.3 & 44.1 & 23.3 & $R$ & -112.2 & 62.8 & 23.3 & $R$ \\
\hline$\delta_{m}=0$ & -148.7 & 28.4 & 10.1 & $R$ & -178.3 & 45.8 & 10.1 & $R$ & -83.4 & 31.2 & 10.1 & $R$ & -94.8 & 21.7 & 10.1 & $R$ & -138.7 & 34.4 & 10.1 & $R$ \\
\hline \multicolumn{9}{|c|}{ Hypothesis (restriction) } & \multicolumn{3}{|l|}{$L\left(H_{0}\right)$} & \multicolumn{3}{|l|}{$\lambda$} & \multicolumn{2}{|l|}{$x^{2}$} & \multicolumn{4}{|c|}{ Decision } \\
\hline \multicolumn{12}{|c|}{ Pooled sample versus sum of individual log-likelihood } & \multicolumn{3}{|c|}{13.4} & \multicolumn{2}{|c|}{45.6} & \multicolumn{4}{|c|}{ Do not reje } \\
\hline
\end{tabular}

Agro-ecological zones share same technology. Critical values are at $5 \%$ significance level and are obtained from $X^{2}$ distribution table 
frontier model are also presented in Table 4. The gamma $(\gamma)$ value calculated for the respondents was 0.999 . The closeness of this value to one (1) and the high Lambda $(\lambda)$ value imply inefficiencies in maize production in the study area. This also makes the stochastic frontier model appropriate for the study [33]. The results therefore suggest that about $0.1 \%$ of the variations in maize outputs for the maize farmers are as a result of the presence of random shocks outside the control of the farmer. Examples of these random shocks include bad weather, diseases, topology, bushfires as well as statistical errors in measuring data. The values of $\lambda(p<0.01)$ and $\sigma^{2}(p<0.1)$ indicate a good fit of the model and correctness of the specified distributional assumptions.

Table 4 also presents statistically significant Wald Chisquare statistic of $3.1 \times 10^{10}(p<0.01)$, indicating joint significance of the model. The variables included in the model were tested for multicollinearity using variance inflation factor (VIF). The mean VIF calculated for the model is 1.252 . This is small and implies that there was no problem of multicollinearity with the model [18]. In addition, the statistically insignificant Breusch Pagan (BP) statistic of 0.566 indicates homoscedasticity of the model.

The results of the production function analysis showed that whereas fertilizer $(p<0.1)$, herbicides $(p<0.01)$, pesticides $(p<0.05)$ and farm size $(p<0.01)$ positively influenced maize output, the effect of labour input $(p<0.01)$ was negative (Table 5). The production elasticities for fertilizer, herbicide, pesticide, farm size and labour inputs are $0.49,0.18,0.01,1.15$ and -0.25 , respectively (Table 6). Also, the return to scale of 3.327 (Table 6) suggests maize production activities in the study area exhibit increasing returns to scale implying that outputs of Ghanaian maize farmers, especially those in the study area, could be increased with increase in intensity of use of

Table 4 Variance parameters for the production function. Source: Survey, 2015

\begin{tabular}{lll}
\hline Variable & Parameter & SE \\
\hline Sigma squared $\sigma^{2}=\sigma_{u}^{2}+\sigma_{v}^{2}$ & $0.722^{*}$ & 0.006 \\
Gamma $\gamma=\sigma_{u}^{2} / \sigma^{2}$ & $0.999^{* * *}$ & 0.046 \\
Lambda $\lambda=\sigma_{u} / \sigma_{v}$ & $3,764,018^{* * *}$ & 0.009 \\
Log-likelihood & -246.316 & \\
Mean technical efficiency & 58.1 & \\
Sample size & 576 & \\
Wald statistic & $3.1 \times 10^{10 * * *}$ & \\
Mean variance inflation factor (VIF) & 1.252 & \\
Breusch Pagan statistic & 0.566 & \\
\hline
\end{tabular}

The asterisks indicate levels of significance. ${ }^{* * *}$ is significant at $1 \%,{ }^{* *}$ is significant at $5 \%$, and * is significant at $10 \%$ herbicide, fertilizer, farm size and pesticides. This finding is in line with the results of similar work done by [31] which reported the influence of herbicide, seed, labour, cost of intermediate inputs and farm size on the output of maize. With maize being the main economic and staple crop for Ghana's rural households, the influence of the above variables on maize output is critical to devising strategies aimed at meeting the sustainable development goals on no poverty and zero hunger.

\section{Technical efficiency of the farmers}

The mean technical efficiency of the maize farmers was estimated to be $58.1 \%$, with a standard deviation of $23.5 \%$ and $0.6 \%$ and $99.9 \%$ as the minimum and maximum, respectively, indicating that the farmers are inefficient with $41.9 \%$ of potential maximum output (6.0 metric tonnes per ha) lost to inefficiency. It could therefore be inferred that maize farmers in Ghana are on average $58.1 \%$ technically efficient in the use of the technologies available to them. The results imply that the outputs of Ghanaian maize farmers and more importantly those in the study area can be increased by $42 \%$ if they are able to use the resources available to them more efficiently. Since technical efficiency is key to enhancing farm incomes and ensuring food security, the finding presents a direction for meeting the sustainable development goals on no poverty and zero hunger. The results corroborate those of previous similar studies in Ghana [2, 3, 13, 20, 24, 31, 38].

The distribution of technical efficiency scores among maize farmers is presented in Fig. 1. The figure shows that majority of maize farmers in the sample $(71 \%)$ have technical efficiencies ranging from 41 to $60 \%$. The implication is that most maize farmers in Ghana have at least $40 \%$ of their potential output lost to inefficiency and this development is worrying as it presents an impression of Ghana struggling to meet the sustainable development goals on no poverty and zero hunger.

\section{Sources of technical efficiency variations in Ghanaian maize farms}

From the inefficiency model presented by Table 7 , a negative coefficient implies an increase in the variable concerned would increase technical efficiency and productivity and vice versa. The coefficient of use of fertilizer by farmers in the sample has the expected negative sign and is statistically significant at the $10 \%$ level. This suggests that maize farmers who use fertilizer produce maize more efficiently. The implication is that fertilizer plays an important role in ensuring technical efficiency of maize farmers in all the maize growing areas of Ghana. This makes the results of [15] that found significant positive relationship between fertilizer use and technical efficiency in developing country 
Table 5 Maximum likelihood estimates of stochastic frontier production functions for pooled and separate ecological zones. Source: Survey, 2015

\begin{tabular}{|c|c|c|c|c|c|c|c|c|c|c|}
\hline \multirow[t]{2}{*}{ Variable } & \multicolumn{2}{|l|}{ Pooled } & \multicolumn{2}{|c|}{$\begin{array}{l}\text { Northern Savannah } \\
\text { zone }\end{array}$} & \multicolumn{2}{|c|}{ Transition zone } & \multicolumn{2}{|l|}{ Forest zone } & \multicolumn{2}{|c|}{$\begin{array}{l}\text { Coastal Savannah } \\
\text { zone }\end{array}$} \\
\hline & Coeff & SE & Coeff & SE & Coeff & SE & Coeff & SE & Coeff & SE \\
\hline Constant & 6.141 & & 6.841 & 0.373 & $10.280^{* * *}$ & 0.505 & 11.176 & & 9.154 & \\
\hline InFET & $0.036^{*}$ & 0.020 & $0.175^{* * *}$ & 0.023 & $0.032^{* * *}$ & 0.008 & $0.028^{* *}$ & 0.012 & $0.077^{* * *}$ & 0.015 \\
\hline InHEB & $0.285^{* * *}$ & 0.084 & 0.358 & 0.046 & $-0.385^{* * *}$ & 0.075 & $1.549^{* *}$ & 0.770 & 0.190 & 0.199 \\
\hline InPET & $0.009^{* *}$ & 0.004 & $0.044^{*}$ & 0.004 & $0.192^{* * *}$ & 0.048 & $0.012^{* *}$ & 0.011 & $0.001^{*}$ & 0.002 \\
\hline InSED & 0.025 & 0.016 & -0.030 & 0.048 & $-0.101^{* * *}$ & 0.018 & $2.607^{* * *}$ & 0.783 & $0.070^{* * *}$ & 0.010 \\
\hline $\ln L A B$ & $-0.287^{* * *}$ & 0.076 & -0.363 & 0.005 & -0.183 & 0.001 & 0.123 & 0.466 & $-1.617^{* * *}$ & 0.200 \\
\hline InMAN & -0.005 & 0.004 & $0.045^{* * *}$ & 0.009 & $0.150^{* * *}$ & 0.040 & 0.011 & 0.011 & $0.050^{* * *}$ & 0.003 \\
\hline $\ln L A D$ & $0.726^{* * *}$ & 0.143 & $0.708^{* * *}$ & 0.161 & $0.548^{* *}$ & 0.244 & $2.658^{* * *}$ & 0.339 & -0.507 & 0.351 \\
\hline InCAP & -0.044 & 0.031 & $-0.295^{* * *}$ & 0.052 & $-0.199^{* * *}$ & 0.063 & -0.461 & 0.577 & $-0.217^{* *}$ & 0.091 \\
\hline $\operatorname{InFET} \times \operatorname{InFET}$ & $-0.008^{* * *}$ & 0.002 & $-0.013^{* * *}$ & 0.003 & $-0.022^{* * *}$ & 0.003 & -0.001 & 0.005 & $0.050^{* * *}$ & 0.002 \\
\hline $\operatorname{InPET} \times \ln P E T$ & 0.009 & 0.017 & -0.072 & 0.063 & -0.001 & 0.013 & $-0.069^{* * *}$ & 0.019 & $-0.085^{* * *}$ & 0.008 \\
\hline InHEB $\times$ InHEB & $-0.038^{* * *}$ & 0.011 & $-0.215^{* * *}$ & 0.023 & $-0.147^{* * *}$ & 0.043 & 0.063 & 0.047 & $0.064^{* * *}$ & 0.006 \\
\hline $\ln S E D \times \ln S E D$ & $-0.098^{* * *}$ & 0.009 & $-0.055^{* * *}$ & 0.021 & $-0.082^{* *}$ & 0.032 & 0.314 & 0.263 & $-0.100^{* *}$ & 0.046 \\
\hline $\ln L A B \times \ln L A B$ & $-0.016^{* *}$ & 0.008 & 0.010 & 0.013 & $-0.032^{* * *}$ & 0.007 & $-0.062^{* *}$ & 0.027 & $0.221^{* * *}$ & 0.013 \\
\hline InMAN $\times$ InMAN & $-0.005^{* *}$ & 0.002 & $-0.002^{* * *}$ & 0.005 & $-0.053^{* * *}$ & 0.006 & $-0.008^{* *}$ & 0.003 & $-0.019^{* * *}$ & 0.001 \\
\hline $\ln L A D \times \ln L A D$ & 0.018 & 0.021 & $0.099^{* *}$ & 0.047 & -0.130 & 0.109 & $0.129^{* *}$ & 0.064 & $-0.581^{* * *}$ & 0.101 \\
\hline $\ln C A P \times \ln C A P$ & $-0.010^{* * *}$ & 0.003 & $0.009^{* *}$ & 0.004 & $-0.003^{*}$ & 0.002 & 0.001 & 0.005 & $-0.018^{* * *}$ & 0.004 \\
\hline $\operatorname{InFET} \times \ln P E T$ & $0.036^{* * *}$ & 0.010 & $-0.019^{* *}$ & 0.010 & 0.008 & 0.011 & 0.012 & 0.010 & $-0.096^{* * *}$ & 0.003 \\
\hline $\operatorname{InFET} \times \operatorname{InHEB}$ & -0.002 & 0.003 & $-0.014^{* * *}$ & 0.004 & $0.002^{*}$ & 0.001 & 0.001 & 0.005 & $-0.019^{* * *}$ & 0.001 \\
\hline $\operatorname{InFET} \times \ln S E D$ & 0.007 & 0.005 & $0.051^{* *}$ & 0.024 & $-0.042^{* *}$ & 0.013 & $0.075^{* * *}$ & 0.012 & $-0.084^{* * *}$ & 0.014 \\
\hline $\ln F E T \times \ln L A B$ & -0.004 & 0.003 & 0.008 & 0.025 & $0.032^{* *}$ & 0.013 & $-0.005^{* * *}$ & 0.002 & $-0.038^{* * *}$ & 0.008 \\
\hline $\ln F E T \times \operatorname{InMAN}$ & $-0.004^{* *}$ & 0.002 & $-0.053^{* * *}$ & 0.008 & $0.016^{* * *}$ & 0.003 & $0.017^{* *}$ & 0.008 & $0.006^{* * *}$ & 0.002 \\
\hline $\ln F E T \times \ln L A N$ & $0.003^{* *}$ & 0.003 & $-0.099^{* * *}$ & 0.022 & 0.001 & 0.002 & $0.006^{* *}$ & 0.003 & $0.014^{* * *}$ & 0.010 \\
\hline $\ln P E T \times \ln C A P$ & $0.005^{* * *}$ & 0.002 & $0.015^{* * *}$ & 0.001 & $0.035^{* * *}$ & 0.006 & -0.007 & 0.005 & $-0.011^{* * *}$ & 0.001 \\
\hline InPET $\times$ InHEB & $-0.032^{* * *}$ & 0.009 & $0.026^{*}$ & 0.014 & $0.110^{* * *}$ & 0.008 & -0.018 & 0.012 & $-0.019^{* * *}$ & 0.003 \\
\hline $\ln S E D \times \ln L A B$ & $-0.044^{* *}$ & 0.020 & 0.035 & 0.026 & $-0.083^{* * *}$ & 0.013 & 0.087 & 0.172 & 0.122 & 0.085 \\
\hline $\ln S E D \times \operatorname{InMAN}$ & -0.011 & 0.020 & $0.109^{* * *}$ & 0.015 & $-0.111^{* * *}$ & 0.017 & $-0.021^{* *}$ & 0.010 & -0.012 & 0.032 \\
\hline $\ln S E D \times \ln L A D$ & $-0.164^{* * *}$ & 0.034 & 0.028 & 0.039 & $0.105^{* * *}$ & 0.052 & $-0.518^{* *}$ & 0.227 & $0.763^{* * *}$ & 0.090 \\
\hline $\operatorname{InSED} \times \operatorname{InCAP}$ & -0.006 & 0.007 & $0.038^{* * *}$ & 0.011 & $0.100^{* * *}$ & 0.028 & 0.217 & 0.191 & $0.205^{* * *}$ & 0.052 \\
\hline $\operatorname{InSED} \times \ln \mathrm{HEB}$ & $0.046^{* * *}$ & 0.015 & 0.015 & 0.019 & $0.124^{* * *}$ & 0.011 & $0.481^{*}$ & 0.250 & $0.170^{* * *}$ & 0.011 \\
\hline $\ln L A B \times \operatorname{InMAN}$ & $0.026^{* * *}$ & 0.008 & $0.086^{* * *}$ & 0.026 & $-0.055^{* * *}$ & 0.013 & -0.031 & 0.023 & $0.071^{* * *}$ & 0.010 \\
\hline $\ln L A B \times \ln \angle A D$ & 0.041 & 0.015 & 0.042 & 0.021 & $0.272^{* * *}$ & 0.023 & -0.015 & 0.187 & $-0.321^{* * *}$ & 0.065 \\
\hline $\ln L A B \times \ln C A P$ & -0.009 & 0.009 & $0.041^{* *}$ & 0.018 & -0.014 & 0.009 & -0.006 & 0.016 & $-0.048^{*}$ & 0.029 \\
\hline $\ln L A B \times \ln H E B$ & $-0.104^{* * *}$ & 0.011 & $-0.099^{* * *}$ & 0.013 & -0.002 & 0.018 & 0.057 & 0.048 & 0.025 & 0.050 \\
\hline $\ln M A N \times \ln L A D$ & $0.012^{* * *}$ & 0.023 & 0.334 & 0.013 & $0.309^{* * *}$ & 0.108 & 0.002 & 0.032 & $-0.015^{* * *}$ & 0.003 \\
\hline InMAN $\times \operatorname{InCAP}$ & 0.002 & 0.003 & $0.079^{* * *}$ & 0.008 & $0.016^{* *}$ & 0.007 & 0.002 & 0.002 & $0.033^{* * *}$ & 0.010 \\
\hline InMAN $\times \operatorname{InHEB}$ & $0.015^{* *}$ & 0.006 & $0.111^{* * *}$ & 0.012 & $-0.022^{* * *}$ & 0.004 & -0.003 & 0.016 & -0.007 & 0.005 \\
\hline $\ln \angle A D \times \operatorname{InCAP}$ & 0.013 & 0.008 & -0.003 & 0.014 & $-0.105^{* * *}$ & 0.028 & -0.233 & 0.166 & -0.062 & 0.040 \\
\hline $\operatorname{InLAD} \times \operatorname{InHEB}$ & $-0.006^{* * *}$ & 0.002 & $-0.005^{* * *}$ & 0.001 & $-0.093^{* * *}$ & 0.013 & $-0.533^{* *}$ & 0.272 & $-0.343^{* * *}$ & 0.043 \\
\hline $\operatorname{InCAP} \times \operatorname{InHEB}$ & -0.005 & 0.001 & 0.002 & 0.002 & -0.012 & 0.001 & $-0.011^{* *}$ & 0.005 & $-0.127^{* * *}$ & 0.011 \\
\hline $\ln F E T \times \ln C A P$ & -0.003 & 0.002 & $-0.005^{* *}$ & 0.002 & $-0.017^{* * *}$ & 0.002 & $-0.041^{* *}$ & 0.012 & $0.014^{* * *}$ & 0.003 \\
\hline $\operatorname{InPET} \times \operatorname{InSED}$ & $-0.004^{* *}$ & 0.001 & $-0.012^{* * *}$ & 0.003 & $-0.014^{* * *}$ & 0.001 & $-0.008^{* * *}$ & 0.001 & $-0.001^{*}$ & 0.001 \\
\hline $\ln P E T \times \ln L A B$ & 0.001 & 0.0004 & $0.003^{* * *}$ & 0.001 & $0.004^{* * *}$ & 0.001 & $-0.002^{*}$ & 0.001 & $0.002^{* *}$ & 0.001 \\
\hline $\operatorname{InPET} \times \operatorname{InMAN}$ & 0.006 & 0.006 & 0.037 & 0.057 & $0.138^{* * *}$ & 0.007 & $-0.042^{* * *}$ & 0.015 & $-0.048^{* * *}$ & 0.003 \\
\hline InPET $\times$ InLAD & 0.001 & 0.003 & -0.018 & 0.043 & $-0.021^{* * *}$ & 0.003 & $0.013^{* *}$ & 0.005 & $0.007^{* * *}$ & 0.002 \\
\hline Log-likelihood & -246.316 & & 17.71978 & & 21.18604 & & 32.206377 & & 64.88732 & \\
\hline
\end{tabular}


Table 6 Input elasticities. Source: Survey, 2015

\begin{tabular}{lc}
\hline Input & Elasticity \\
\hline Quantity of fertilizer & 0.49 \\
Quantity of herbicide & 0.18 \\
Quantity of pesticide & 0.01 \\
Quantity of seed & 0.73 \\
Quantity of labour & -0.25 \\
Quantity of manure & -0.05 \\
Quantity of land & 1.15 \\
Quantity of capital & -0.49
\end{tabular}

Scale elasticity, 3.327

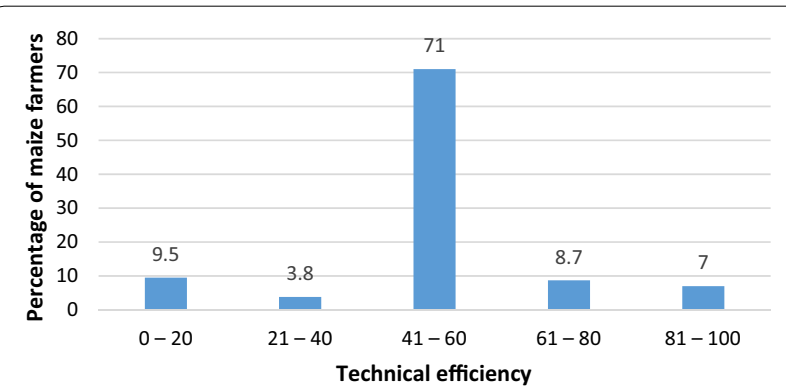

Fig. 1 Distribution of technical efficiency of maize farmers. Source: Survey, 2015

agriculture still relevant. Therefore, for maize farmers' incomes to be improved as well as being food secure, it is important that mechanisms are put in place to make it more attractive for them to use recommended doses of fertilizer in their farms. The effect of the dummy for improved seeds on technical inefficiency for maize farmers in the sample is negative and is expected. The variable is statistically significant at the $1 \%$ level. The implication is that maize farms with improved maize seeds are more technically efficient than farms using traditional seeds. This could be due to the fact that most improved seeds are high yielding. This finding on improved seed use, however, disagrees with the finding of [38] that suggest that technical inefficiency of maize farmers increases with use of improved seeds. According to [38], improved varieties of maize come along with certain agronomic practices which farmers must follow in order to get the maximum level of potential output. However, farmers ranked high cost of inputs as their most pressing problem, and therefore, most of them could not buy the recommended inputs that go with improved varieties. As Ghana strives to achieve the sustainable development goals on no poverty and zero hunger by especially mounting the planting for food and jobs programme, the findings of this
Table 7 Sources of technical efficiency among maize farmers. Source: Survey, 2015

\begin{tabular}{lll}
\hline Variable & Coefficient & SE \\
\hline Constant & -0.289 & 0.477 \\
Access to good roads & 0.478 & 0.209 \\
Living in Northern Savannah zone & $-0.642^{* * *}$ & 0.275 \\
Living in Transitional zone & -0.234 & 0.318 \\
Living in Forest zone & $-0.881^{* *}$ & 0.399 \\
Gender of maize farmer & $-0.222^{* *}$ & 0.164 \\
Age of maize farmer & 0.007 & 0.007 \\
Educational level of maize farmer & $-0.044^{* * *}$ & 0.016 \\
Household size of maize farmer & -0.012 & 0.016 \\
Experience of maize farmer & $-0.003^{* *}$ & 0.009 \\
Farm size & $0.014^{*}$ & 0.007 \\
Land fragmentation & $0.007^{*}$ & 0.033 \\
Income & -0.0001 & 0.00002 \\
Extension contact & $-0.302^{*}$ & 0.177 \\
Membership of farmer association & $-0.202^{* *}$ & 0.200 \\
Access to credit & -0.058 & 0.197 \\
Access to ready market & -0.294 & 0.203 \\
Fertilizer use & $-0.193^{*}$ & 0.180 \\
Pesticide use & -0.431 & 0.402 \\
Improved seed use & $-0.529^{* * *}$ & 0.143 \\
\hline
\end{tabular}

The asterisks indicate levels of significance. ${ }^{* * *}$ is significant at $1 \%,{ }^{* *}$ is significant at $5 \%$, and ${ }^{*}$ is significant at $10 \%$

study presents a word of caution to forcing farmers to use specified improved seeds which may present other production challenges to them.

The coefficient for maize farming experience with negative sign is expected and is statistically significant at the $5 \%$ level. The implication is that experience maize farmers are more technically efficient in the production of maize than inexperienced ones. This is because farmers with many years of maize farming experience will more likely be familiar with the required skills needed for maize production and therefore are more likely to have higher outputs and consequently more technically efficient. This agrees with the findings of [23] that found the number of years in maize farming to have a negative effect on technical inefficiency. The results of the current study also agree with the findings of [2] that concluded that farmers with many years of experience are more technically efficient than those with fewer years.

The coefficient of the dummy representing membership to a farmer association is negatively related to technical inefficiency and statistically significant at $5 \%$. This implies that maize farmers who belong to farmer associations are more technically efficient than those who do not belong to any farmer group. This is because most agricultural technologies and new methods of farming are normally disseminated through farmer-based organizations 
so it is likely that it is only farmers who are members of such associations that will have access to improved technological packages. This finding is in agreement with [29] that farmers who are members of farmer groups are more efficient and productive because they have more access to extension services even though it contradicts the finding of [24]. Such farmers will likely have higher average incomes and will not struggle having a three square meal on daily basis.

The effect of education on technical efficiency is positive and significant at $1 \%$. The results show that formally educated farmers produce maize more efficiently than those with no formal education. This is true since human capital represented by educational level enhances the managerial and technical skills of farmers. According to [11], education is hypothesized to increase farmers' ability to utilize existing technologies and attain higher efficiency levels. The importance of education of farmers in their use of productivity enhancing technologies is discussed extensively in the literature. According to [25, 40], farmers with many years of education are thought to have greater ability to notice, explain the meaning and respond to new information about productivity enhancing technologies than their counterparts with less number of years of education. Farmers who have received formal education are therefore able to access information from extension agents, which affect their use of production technologies. Furthermore, [42] reported that educational level and the producer's economic status, that influence ability to purchase and use productivity enhancing technologies, are to a larger extent positively related, most especially for farmers in less developed economies. The implication is that educated farmers are expected to be more efficient to understand and obtain new technologies in a shorter period of time than uneducated ones. Also, [36] notes that the complexity of a technology often poses a negative effect on improved input use and that education is thought to reduce the amount of complexity perceived in a technology thereby increasing its use and consequently, making the farmer technically efficient, receiving higher incomes and never going hungry. Djokoto and Gidiglo [17] also suggests that efficiency improving measures including training in farm management (a form of education), are required to make up for the mean technical efficiency difference of $38 \%$ experienced by agribusiness firms in Ghana.

The effect of male gender on technical inefficiency is negative for the maize farmers, and this is significant at $5 \%$. The results show that males are more technically efficient in maize production than females. This corroborates the findings of $[2,38,39]$ in technical efficiency studies that found negative relationships between gender and technical inefficiency. The negative effect of gender on technical inefficiency can be attributed to the crucial roles women perform in the domestic and economic life of society which negatively affect their technical efficiency. This comprises the unmeasured non-economic activities such as child care, cooking, cleaning, etc., performed by females in the household.

The influence of farm size is positive and significant at the $10 \%$ level. This means that an increase in farm size by maize farmers will cause a decline in the technical efficiency of such farmers. The reason is that most farmers are poor and may not have the required resources to meet the production demands of large farms. This, however, disagrees with the findings of $[8,9,35]$ that reported a negative correlation between farm size and technical inefficiency.

The influence of land fragmentation on technical inefficiency is also positive and is statistically significant at $10 \%$. This means that owning many farm plots by maize farmers in Ghana causes inefficiencies in maize production. The reasons may include but not limited to losses due to increased travel time, waste of border spaces, ineffective monitoring as well as inability to use farm machinery. This is in line with the results of [35] that reported an inverse correlation between land fragmentation and efficiency of agricultural production. Existence of production inefficiency has the potential to make farmers poor and hungry, and this is a threat to meeting the first two sustainable development goals (no poverty and zero hunger).

Access to extension is positively related to technical efficiency of maize farmers, and this is significant at $10 \%$. The implication is that access to extension service will increase the technical efficiency of maize farmers in Ghana and contribute to achieving the sustainable development goals of no poverty and zero hunger. This is because agricultural production technologies developed by research institutes reach farmers through agricultural extension officers. Extension therefore allows maize farmers to be abreast with the latest recommended farming methods and technologies that are believed will enhance agricultural productivity and efficiency. Several studies including $[4,8,10]$, as well as $[38,41]$ among others have also reported a positive relationship between access to extension service and technical efficiency of farmers.

Finally, the influence of the variables representing maize farms in the Northern Savannah, Transitional and Forest zones on the technical inefficiency of maize production is negative, indicating that improvement in technical efficiency of maize production is independent of agro-ecological zone. The variable representing maize farms in the Northern Savannah zone is significant at the $1 \%$ level, while that of maize farms in the Forest zone is 
significant at the $5 \%$ significance level. The results suggest that maize producers in all agro-ecological zones have equal chances of increasing their technical efficiencies and that maize production can take place in every agroecological zone. The result is in line with the results of [3] in a study into the technical efficiency of maize farmers across various agro-ecological zones of Ghana that revealed positive relationships between variables representing various agro-ecological zones and the technical efficiency of maize production in Ghana. Similar results were also obtained by $[24,31]$ whose studies revealed that whether or not a maize farmer is technically efficient is independent of growing location. The implication is that, as Ghana strives to achieve the first two sustainable development goals, steps can be taken to improve technical efficiency of maize farmers in all four agro-ecological zones.

\section{Conclusion}

Whether or not maize farmers are technically efficient determines their choice of productivity improvement strategy and very important for achieving the sustainable development goals on no poverty and zero hunger. This study examines technical efficiency and its determinants of Ghana's maize farmers. The study reveals that the mean technical efficiency estimate for maize farmers in Ghana is $58.1 \%$, indicating that maize farmers in Ghana produce below the frontier with $41.9 \%$ of potential maximum output lost to technical inefficiency. This development, if unchecked, could threaten Ghana's achievement of the sustainable development goals on no poverty and zero hunger. It also reveals that an increase in educational level, maize farming experience, extension contact as well as uses of fertilizer and improved seeds would increase the technical efficiency of maize producers in Ghana. That is, human capital represented by educational level enhances the managerial and technical skills of farmers. Experience farmers will more likely be familiar with the required skills needed for maize production. Agricultural production technologies developed by research institutes also reach farmers through agricultural extension officers. Fertilizer also enriches the fertility of the soil, and most improved seeds are high yielding. Similarly, male Ghanaian maize farmers are more technically efficient than female farmers. This can be attributed to the crucial roles women perform in the domestic and economic life of society which negatively affect their technical efficiency. Furthermore, membership of a farmer association will increase the technical efficiency of Ghanaian maize farmers because extension officers normally disseminate most efficiency enhancing technologies through farmer groups. Finally, an increase in farm size and land fragmentation will decrease technical efficiency of Ghana's maize farmers. This is because farmers may find it difficult meeting the requirements of maintaining large farms and land fragmentation may lead to losses because of increased travel time, waste of border spaces, ineffective monitoring as well as inability to use farm machinery.

Given that increase in formal education will increase technical efficiency, efficiency improvement programmes by stakeholders in the maize industry could target literate maize farmers. Stakeholders, especially the Ministry of Food and Agriculture (MOFA) could also liaise with the Non-Formal Education Division of the Ministry of Education to provide maize farmers who do not have formal education with special training in at least reading, writing and numeracy prior to introducing new efficiency enhancing programmes to such farmers. The finding on the poor number of maize farmers that had access to agricultural extension service suggests that policy makers through the Ministry of Food and Agriculture should analyse the problems extension officers face in the discharge of their duties. This will pave the way for the provision of appropriate incentives to extension officers by government and other stakeholders in the maize industry that will help improve their commitment to delivery of agricultural extension services to the maize farmers. It is worthy of note that the current efficiency study dwelt on the fact that Ghana's maize farmers use the same technology. However, the importance of the existence of possible technological heterogeneity among farmers in recent times cannot be overemphasized and therefore requires further investigation. Future efficiency and productivity researchers are therefore encouraged to still consider the existence of specific technologies used by maize farmers in different agro-ecological zones to pave the way for analysing the effect of technology gaps across agro-ecological zones. There is no gainsaying the fact that paying attention to the above recommendations will help develop Ghana's maize sector through increased technical efficiency of her maize farmers and consequently contribute to achieving her quest to meeting the sustainable development goals on no poverty and zero hunger.

\section{Abbreviations \\ BP: Breusch Pagan; JHS: Junior High School; JSS: Junior Secondary School; SSS: Senior Secondary School; SHS: Senior High School; MLE: maximum likelihood estimation; MOFA: Ministry of Food and Agriculture; SRID: Statistics, Research and Information Directorate; VIF: variance inflation factor; COLS: corrected ordinary least squares; NAADS: National Agricultural Advisory Services.}

\section{Authors' contributions}

CAW conceived the idea and was responsible for analysis of the data as well as preparation of the manuscript. DAV was responsible for designing the study and data collection. Both authors read and approved the final manuscript.

Acknowledgements

We are especially indebted to the staff of the Ministry of Food and Agriculture in the West Mamprusi, East Gonja, Nkoranza, Ejura Sekyedumase, Fanteakwa, 
Sekyere South, Gomoa and Ketu districts/municipalities of Ghana for the information they provided about the maize crop and also assisting in the data collection. We are also grateful to the respondent maize farmers in the aforementioned districts/municipalities without whose co-operation the study could not have taken place.

\section{Competing interests}

The authors declare that they have no competing interests.

\section{Availability of data materials}

Not applicable.

\section{Consent for publication}

Not applicable.

\section{Ethics approval and consent to participate} Not applicable.

\section{Funding}

Not applicable.

\section{Publisher's Note}

Springer Nature remains neutral with regard to jurisdictional claims in published maps and institutional affiliations.

\section{Received: 20 February 2018 Accepted: 1 October 2018}

Published online: 05 October 2018

\section{References}

1. Abdulai A, Eberlin R. Technical efficiency during economic reform in Nicaragua: evidence from farm household survey data. Econ Syst. 2001;25:113-25

2. Abdulai S, Nkegbe PK, Donkoh SA. Technical efficiency of maize production in Northern Ghana. Afr J Agric Res. 2013;8(43):5251-9.

3. Addai KN, Owusu V. Technical efficiency of maize farmers across various agro ecological zones of Ghana. J Agric Environ Sci. 2014;3(1):149-72.

4. Ahmad MC, Ghulam M, Igbal M. Wheat productivity, efficiency, and sustainability: a stochastic production frontier analysis. Pakistan Dev Rev. 2002;41:4.

5. Aigner DK, Lovell CK, Schmidt P. Formulation and estimation of stochastic frontier production function models. J Econom. 1977;6:21-37.

6. Ajao AO. Empirical analysis of agricultural productivity growth in SubSahara Africa: 1961-2003. Libyan Agric Res Cent J Int. 2011;2(5):224-31.

7. Amaza P, Kwacha A, Kamara A. Farmers' perceptions, profitability, and factors influencing the adoption of improved maize varieties in the Guinea Savannas of Nigeria. Africa: IITA: Research to Nourish Africa; 2007.

8. Amos TT. Analysis of productivity and technical efficiency of smallholder cocoa farmers in Nigeria. J Soc Sci. 2007;15:127-33.

9. Barnes A. Technical efficiency estimation of Scottish agriculture: a note. J Agric Econ. 2008;59:370-6.

10. Basnayake BMJK, Gunaratne LHP. Estimation of technical efficiency and it's determinants in the tea small-holding sector in the mid country Wet Zone of Sri Lanka. Sri Lanka J Agric Econ. 2002;4:137-50.

11. Battese GE, Coelli TJ. A model for technical efficiency effects in a stochastic frontier production for panel data. Empir Econ. 1995;20:325-32.

12. Battese GE, Prasada Rao DS, O'Donnell CJ. A metafrontier production function for estimation of technical efficiencies and technology gaps for firms operating under different technologies. J Prod Anal. 2004;21:91-103.

13. Bempomaa B, Acquah HDG. Technical efficiency analysis of maize production: evidence from Ghana. APSTRACT: Appl Stud Agribus Commer. 2014:8(2-3):73-9.

14. Bonabana-Wabbi J. Assessing factors affecting adoption of agricultural technologies: the case of integrated pest management (IPM) in Kum District, Eastern Uganda. Unpublished Masters Dissertation, Virginia Polytechnic Institute and State University, Blacksburg, Virginia; 2002.
15. Bravo-ureta BE, Evenson RE. Efficiency in agricultural production: the case of peasant farmers in eastern Paraguay. J Int Assoc Agric Econ. 1994:10(1):27-8.

16. Bravo-Ureta BE, Robert EE. Efficiency in agricultural production: a case of peasant farms in eastern Paraguay. Agric Econ. 1993;10:27-37.

17. Djokoto JG, Gidiglo KF. Technical efficiency in agribusiness: a meta-analysis on Ghana. Agribusiness. 2016;32(3):397-415.

18. Edriss AK. A passport to research methods. Las Vegas: International Publishers and Press; 2003.

19. Elsamma J, George MV. Technical efficiency in rice production: a frontier production function approach. Agric Econ Res Rev. 2002;15:50-5.

20. Essilfie FL, Asiamah MT, Nimoh F. Estimation of farm level technical efficiency in small scale maize production in the Mfantseman Municipality in the Central Region of Ghana: a stochastic frontier approach. J Dev Agric Econ. 2011;3(14):645-54.

21. Green WH. Limdep version 8.0: econometric modeling guide. New York: Econometric Software, Inc; 2002.

22. Greene WH. Econometric analysis. New York: Pearson Education; 2005

23. Isaac O. Technical efficiency of maize production in Oyo state. J Econ Int Finance. 2011:3(4):211-6.

24. Kuwornu JKM, Amoah E, Seini W. Technical efficiency analysis of maize farmers in the eastern region of Ghana. J Soc Dev Sci. 2013;4(2):84-99.

25. Langyintuo A, Mekuria M. Modeling agricultural technology adoption using the software STATA. CIMMYT-ALP training manual no. 1/2005 (Part Two). International Maize and Wheat Improvement Center, Harare, Zimbabwe; 2005.

26. Meeusen W, van den Broeck J. Efficiency estimation from Cobb-Douglas production functions with composed error. Int Econ Rev. 1977;18:435-44.

27. MOFA (Ministry of Food and Agriculture). Agriculture in Ghana: facts and figures Statistics, Research and Information Directorate (SRID); 2013.

28. Mohammed I, Wojciech JF, Shashidhara K. The determinants of farmer adoption of improved peanut varieties and their impact on farm income: evidence from northern Ghana. In: Selected paper prepared for presentation at the agricultural and applied economics association annual meeting, Seattle, WA, August 12-14; 2012.

29. NAADS. Proceedings of the mid-term review of the National Agricultural Advisory Services. Kampala, Uganda: NAADS; 2005.

30. Okoboi G. Improved inputs use, productivity and commercialisation in Uganda maize production. Unpublished Doctoral Dissertation, Makerere University; 2011.

31. Oppong BA, Onumah EE, Asuming-Brempong S. Technical efficiency and production risk of maize production: evidence from Ghana. Asian J Agric Ext Econ Soc. 2016;11(3):1-9.

32. Owuor G, Shem OA. What are the key constraints in technical efficiency of smallholder farmers in Africa? Empirical evidence from Kenya. In: A paper presented at 111 EAAE-IAAE seminar'small farms: decline or persistence.' University of Kent, 26-27th June; 2009.

33. Piesse J, Thirtle C. A stochastic frontier approach to firm level efficiency, technological change and productivity during the early transition in Hungary. J Comp Econ. 2000;28:473-501.

34. Ragasa C, Dankyi A, Acheampong P, Wiredu AN, Chapoto A, Asamoah M, Tripp R. Patterns of adoption of improved maize technologies in Ghana. Ghana strategy support program. International Food Policy Research Institute (IFPRI) working paper 36; 2013.

35. Raghbendra J, Hari KN, Subbarayan DP. Land fragmentation and its implications for productivity: evidence from Southern India. Australia South Asia Research Centre (ASARC) working paper 2005/01; 2005.

36. Rogers EM. Diffusion of innovations. 5th ed. New York: Free Press; 2003.

37. Sherlund SM, Barrett CB, Adesina AA. Smallholder technical efficiency controlling for environmental production conditions. J Dev Econ. 2002;69(1):85-101.

38. Sienso G, Asuming-Brempong S, Amegashie DPK. Estimating the efficiency of maize farmers in Ghana. In: Contributed paper prepared for presentation at the 4th international conference of the AAAE, Cape Town, Hammamet, Tunisia, 22-25 September, 2013.

39. Solís D, Bravo-Ureta B, Quiroga RE. Technical efficiency and adoption of soil conservation in El Salvador and Honduras. In: Research paper presented at the international association of agricultural economists conference, Gold Coast, Australia, August 12-18, 2006. 
40. Tabi AJ, Vabi MB, Malaa DK. Adoption of maize and cassava technologies in the forest-savannah zone of Cameroon: implications for poverty reduction. World Appl Sci J. 2010;11(2):196-209.

41. Tchale H, Sauer J. The efficiency of maize farming in Malawi: a bootstrapped translog frontier. Cahiers d’économie et sociologie rurales. 2007;82-83:33-56.

42. UBoS. Uganda national household survey: socio-economic module. Abridged report. Kampala, Uganda: UBoS; 2010.
43. Wilson P, Dave H, Stephen R, Loannis K. Measuring and explaining technical efficiency in uk potato production. J Agric Econ. 1998;48(3):294-305.

44. World Bank. World development report 2008: agriculture for development. Washington, D.C.; 2007.

45. Xu T, Sun F-F, Zhou Y-H. Technical efficiency and its determinants in China's hog production. J Integr Agric. 2015;14:1057-68.
Ready to submit your research? Choose BMC and benefit from:

- fast, convenient online submission

- thorough peer review by experienced researchers in your field

- rapid publication on acceptance

- support for research data, including large and complex data types

- gold Open Access which fosters wider collaboration and increased citations

- maximum visibility for your research: over $100 \mathrm{M}$ website views per year

At BMC, research is always in progress.

Learn more biomedcentral.com/submissions 